\title{
György Lukács e o problema do irracionalismo*
}

\begin{abstract}
Resumo: O artigo destaca a importância do filósofo húngaro György Lukács para a geração alemã marxista do período pós-guerra. Enfatiza a influência que a crítica lukácsiana ao existencialismo exerceu no período e aborda aspectos importantes da obra do autor, do período em questão e os desdobramentos filosóficos de suas obras posteriores.
\end{abstract}

Palavras-chave: marxismo e existencialismo; Lukács e o irracionalismo; marxismo e ontologia; crítica ao existencialismo.

\section{Hans Heinz Holz*}

\begin{abstract}
The article highlights the importance of the Hungarian philosopher György Lukács for the German Marxist generation of the post-war period. It emphasizes the influence that Lukács's critique of existentialism exerted in the period and addresses important aspects of the author's work, the period in question and the philosophical consequences of his later works.
\end{abstract}

Keywords: marxism and existentialism; Lukács and irrationalism; marxism and ontology; criticism of existentialism.

1. Quem fala hoje de Lukács deve falar também da biografia intelectual e política de uma geração, da minha geração, que se pôs a caminho entre as ruínas deixadas pela Segunda Guerra Mundial; e não quero dizer apenas as ruínas materiais, que poderiam nos ensinar um primum vivere, deinde philosophari, ${ }^{1}$ mas também as ruínas espirituais diante das quais nos encontramos devido à destruição da herança cultural e da razão operadas pelo fascismo, por seus preparadores e por seus cúmplices. Naquela ocasião, também aprendemos que aquela verdade latina lapalissiana, ${ }^{2}$ vulgarmaterialista, que separa da compreensão filosófica uma prática de vida inequívoca, relegando a primeira à esfera do luxo, é um erro fatal de princípio, e, para nós, apenas

\footnotetext{
* Tradução de Ronaldo Vielmi Fortes. Revisão técnica de Ester Vaisman. Tradução feita a partir de "György Lukács e il problema dell'irrazionalismo" (traduzione di Clara Grein e revisione di Rosario Musillami). In: MUSILLAMI, Rosario (a cura di). Attualità e rilettura critica di György Lukács e Ernst Bloch. Milano, Diffusioni'84, 1984.

** Hans Heinz Holz (26 de fevereiro de 1927 - 11 de dezembro de 2011) foi um filósofo marxista alemão. Nascido em Frankfurt am Main, foi professor de filosofia na Universidade de Marburgo (de 1971 a 1979) e na Universidade de Groningen (de 1979 a 1993). Autor de diversas obras, dentre as quais se pode destacar: Dialektik und Widerspiegelung (1983); Philosophische Theorie der bildenden Künste (1996-7); Einheit und Widerspruch. Problemgeschichte der Dialektik in der Neuzeit (1997).

${ }_{1}^{1}$ Primeiro viver, depois filosofar [N.T.]

${ }^{2}$ A expressão nasceu do nome de um nobre francês, falecido no século XVI, Jacques de La Palice (ou La Palisse). Quando La Palice faleceu, foi escrito um epitáfio em que constavam as seguintes palavras francesas - s'il n'était pas mort, il ferait encore envie - que querem dizer algo como "se ele não estivesse morto, ainda agora causaria inveja". Porém, alguém as leu incorretamente do seguinte modo: s'il n'était pas mort, il serait encore en_vie - ou seja, alterando-se apenas uma letra e adicionando um único espaço, a frase podia ser lida como "se ele não estivesse morto, ainda agora estaria vivo", o que representa uma ideia mais que óbvia [N.T.].
} 
era válido: não viver nisi philosophari. ${ }^{3} \mathrm{O}$ sétimo congresso mundial do Comintern sabia disso quando vinculou a luta contra o fascismo à luta que conservaria a continuidade de nossa cultura, que salvaria o legado diante do perigo e que desenvolveria, por meio do pensamento, prospectivas de progresso. Mas muito poucos dentre nós ouviram falar dele até 1945.

Agora continuo falando sobre o desenvolvimento daquela parte da Alemanha de onde venho. Depois de doze anos de terror e aniquilamento aterrorizante das organizações, dos quadros e da cultura do movimento operário, as condições objetivas que nos permitiram confrontar as causas do fascismo de um ponto de vista teórico, ideológico - o que significa também de um ponto de vista prático-político - não estavam de forma alguma maduras. Isso era válido, sobretudo, para os intelectuais jovens. Os melhores entre nós haviam se tornado antifascistas por razões éticas, pela inquietação diante da devastação, por convicção do absurdo da ideologia nazista, e apenas alguns poucos, por uma consciência de classe avançada. A liberdade era de grande valor para todos nós, talvez o maior. Mas ainda não erámos capazes de distinguir entre uma fraseologia que fala de liberdade, mas que apenas oculta a exploração capitalista, a opressão colonial, o imperialismo e a luta real, extenuante, pela abolição das condições em que os homens são oprimidos e sua humanidade (para usar a palavra no sentido de Immanuel Kant) maltratada e arruinada. $\mathrm{O}$ antifascismo, a liberdade e o individualismo burguês constituíam uma mistura ideológica; afinal, não poderia ser de outro modo, já que a maioria de nós pertencia à classe burguesa. JeanPaul Sartre ou mesmo Karl Jaspers foram as estrelas ideológicas que nos orientavam (basta olhar os folhetos dos jornais e os programas de cursos das universidades para reconstruir a situação espiritual da época); neles, a tradição da educação burguesa incorporava a aura do antifascismo.

A tradição da educação burguesa - isso era importante para nós, pois era a única coisa que possuíamos que tinha substância teórica e ideológica. Certamente alguns de nós haviam lido Irrweg einer Nation de Alexander Abusch - um grande e importante livro para uma geração desorientada; depois, encontramos os ensaios de Franz Mehring sobre a história prussiano-alemã e a introdução ao marxismo de Fred Oelssner; foram os primeiros instrumentos de orientação, mas igualmente insuficientes

\footnotetext{
${ }^{3}$ Mas filosofar [N.T.]
} 
como alternativas à enorme quantidade de saber e cultura da produção cultural e científica burguesa que nos foi transmitida de forma não valorativa (wertfrel) pelos mesmos professores que haviam servido a Hitler.

Então surgiu György Lukács: sua discussão com Sartre e Jaspers em Rencontres Internationales em Genebra, documentada na revista Umschau já em 1947 por Heinz Maus, que injustamente foi esquecido tão cedo; na edição da Aufbau-Verlag, apareceram, logo depois, seus escritos Fortschritt und Reaktion in der deutschen Literatur, Deutsche Literatur im Zeitalter des Imperialismus, Ensaios Uber den Realismus e Schicksalswende, ${ }^{4}$ aqueles exemplares amarelados que, guardados por motivos sentimentais, são, hoje, objeto de recordação de nossos primeiros momentos de luta ideológica após a Segunda Guerra Mundial. Rico em conhecimento e cultura burguesa, mostrou-nos que a cultura, a literatura e a filosofia são campos, meios e manifestações da luta de classes, que devem ser distinguidos entre um legado do qual queremos fazer parte e um legado que devemos superar; mostrou-nos as grandes obras situadas socialmente, que refletem as contradições de seu tempo e que devemos nos apropriar criticamente de sua substância, determinando seu realismo, sua tendência e sua relação com o progresso; mostrou-nos, com material a nós familiar em mãos, que tomar partido é uma qualidade da verdade. Ele nos desafiou a ousar e a confrontar os conhecimentos acadêmicos que nos foram transmitidos, contra as interpretações de nossos professores universitários por meio de questões críticas e com o objetivo de expô-los com responsabilidade política. Assim, ele se tornou para nós, e especialmente para a parte progressista e politicamente atenta da intelectualidade burguesa, um mestre do marxismo.

2. Como se pode ver, ao falar sobre a biografia ideológica de minha geração, fiz continuamente referências a György Lukács. De uma maneira pessoal, tentei acenar para uma história da recepção. Essa história da adesão deve ser separada do conteúdo sistemático de sua obra, da sua questão interna, do que é certo e do que é errado e também dos erros políticos que Lukács cometeu em sua vida longa e agitada, e que, seguramente, têm a sua origem também nos erros teóricos; são problemas da crítica filosófica, que surgem diante de qualquer obra e que representam um momento do progresso do conhecimento. Gostaria também de separar essa história da adesão que

\footnotetext{
4 Progresso e reação na literatura alemã, Literatura alemã na era do imperialismo, Ensaios sobre o realismo e Viragem do destino. [N.T.].
} 
mencionei da segunda, que não deve ser esquecida de forma alguma, e no decorrer da qual, a partir de História e consciência de classe, revisionistas de todos os tipos seguiram o exemplo de Lukács; e, certamente, nele havia pontos de apoio suficientes para tais afiliações por assim dizer "extraconjugais"; um confronto crítico e, neste caso, também a polêmica são de fato necessários. Mas a crítica, o confronto e a polêmica não devem esconder que em Lukács existe um núcleo substancial que tornou aquela primeira história de adesão possível e duradoura; malgrado todos os enganos e erros, Lukács foi um teórico que pertence positivamente ao contexto da Terceira Internacional; nos pontos essenciais, ele era um leninista, e negligenciar isso significaria lançá-lo aos inimigos ideológicos, aos inimigos de classe (e junto com ele uma parte de nossa própria história intelectual).

Naturalmente, no interior de contextos diferentes, as ênfases terão de ser colocadas de maneira diferente, e aqui posso apenas falar sobre a importância que tanto Lukács quanto a adesão a Lukács têm para a luta ideológica dos marxistas na Europa Ocidental. Mas, do meu ponto de vista, qualquer crítica - à colocação equivocada de sua ontologia, à negligência do aspecto linguístico na obra literária, ao conceito de realismo, ao mesmo tempo muito amplo e estreito, à tendência à acentuação excessiva da subjetividade e, a ela ligada, à elaboração insuficiente da dialética da natureza - deve ser consciente do fato de que ela se apresenta no âmbito do exame e do esclarecimento dos princípios marxistas do espelhamento filosófico. Está em jogo a racionalidade da dialética materialista, e ninguém vai querer sustentar que a sistematicidade e os momentos de suas leis de movimento se apresentam completamente desenvolvidos de uma vez por todas, que a experimentação de modelos de construção não seja indispensável, assim como não o sejam os erros e a refutação de erros, a críticas e autocríticas em vista de um desenvolvimento ulterior da dialética.

Racionalidade da dialética materialista, esta é uma palavra-chave que caracteriza as grandes contribuições de György Lukács no período de luta contra a Alemanha de Hitler e sua ideologia. Foi a insistência no primado da razão que, em um ambiente espiritual pleno de pseudologias ${ }^{5}$ ideológicas, nos fez sentir próximos de György Lukács. Essa insistência não era árida e pedante, mas movida por uma paixão que

\footnotetext{
${ }^{5}$ Tendência patológica para mentiras [N.T.].
} 
surgiu da união da indignação intelectual e moral diante da desumanidade, das atrocidades postas pelas condições capitalistas e pelos horrores fascistas. A luta de Lukács contra o irracionalismo em $A$ destruição da razão (e nas obras paralelas de crítica literária) arde a partir de um fogo emocional, no qual, às vezes, as devidas diferenciações se transformam em cinzas e no qual se queima mais do que seria sensato e necessário. Mas essa emotividade também é sua força. A inquietação face aos efeitos da contrarrazão, a convicção da nocividade social do irracionalismo e o partidarismo, indispensável ao postulado da cientificidade da Weltanschauung, forneceram-lhe a capacidade de definir, independentemente da força fascinante dos grandes ou brilhantes pensadores, a dianteira da luta de classes ideológica, portanto, aprendemos a apontar na direção certa.

"Com a derrota de Hitler - como diz Lukács no pós-escrito, a apresentação de $A$ destruição da razão - que teve início nos dias da plenitude de seu poder, adquiriu um caráter essencialmente histórico". Mas já em 1953, Lukács diagnosticou de maneira justa, precisamente neste pós-escrito, "que o fim da guerra, pelo contrário não significou senão a preparação de uma nova guerra, dessa vez, contra a União Soviética, que o trabalho ideológico sobre as massas com vista à guerra constituía um problema central do mundo imperialista". ${ }^{6} \mathrm{O}$ curso da política dos Estados Unidos de Truman a Reagan confirmou esse diagnóstico em sua nitidez alarmante. Quem teria ousado pensar em 1953 que todas aquelas figuras com as quais Lukács lidou em $A$ destruição da razão voltariam a surgir vinte anos depois como fontes de uma nova onda irracionalista: Friedrich Schlegel, Schopenhauer e Nietzsche no século XIX; Heidegger, Carl Schmitt e Arnold Gehlen no século XX, apenas que transferidas - não muito diferente do que na época em que $A$ destruição da razão surgiu - para um nível infinitamente mais baixo de argumentação e de problematização filosófica. Lukács então escreveu: "exatamente por sua inferioridade moral e política é que Rosenberg se tornou o ideólogo adequado do nacional-socialismo. E se, [hoje], aquele recuo estratégico para Nietzsche e Spengler conduziu a uma nova ofensiva filosófica, o seu protagonista deve - por uma necessidade histórica - representar filosoficamente um nível ainda mais baixo que Rosenberg". ${ }^{7}$ Em consideração às teorias de André

6 Lukács, G. Die Zerstorung der Vernunft, Aufbau-Verlag, Berlin, 1954, p. 603; Werke vol. 9, Luchterhand Verlag, Darmstadt-Neuwied, 1974, p. 663; ed. bras. A destruição da razão, São Paulo: Instituto Lukács, 2020, p. 663.

${ }^{7}$ Ibid., Aufbau-Verlag, p. 9, Werke 9, p. 14; ed. bras., idem, p. 14. modif. 
Glucksmann, esse prognóstico não é de forma alguma contraditado. Aqueles que se encontram hoje na frente da luta ideológica, em uma nação ocidental, estão cientes da atualidade e da utilidade instrumental da crítica de Lukács ao irracionalismo, mesmo que a ferramenta que ele forjou deva ser melhorada e aperfeiçoada.

3. O surgimento de filosofias irracionais ocorre em condições histórico-sociais precisamente determináveis, mas sempre, como justamente observou Lukács, como "uma simples forma de reação ao desenvolvimento dialético da razão humana". ${ }^{8}$ Sua tese é:

\begin{abstract}
que as diferentes etapas do irracionalismo surgiram como respostas reacionárias a problemas da luta de classes. O conteúdo, a forma, o método, o tom etc. de sua reação contra o progresso da sociedade não são determinados por tal dialética interna própria ao pensamento, mas, sobretudo, pelo adversário, pelas condições de luta que são impostas à bourgeoisie reacionária. Isso deve ser fixado como um princípio básico do desenvolvimento do irracionalismo. ${ }^{9}$
\end{abstract}

Quero dizer que o desenvolvimento recente confirma essa minha suposição. Em outro lugar, ${ }^{10}$ mostrei que a história da filosofia na República Federal da Alemanha após 1945 só pode ser entendida como um processo unitário. Se for entendida como uma recusa multifacetada e mutável na sucessão de modas passageiras - mas, em última análise, inalterada na tendência de fundo - contra as posições ideológicas do socialismo científico, em que o assim chamado pluralismo de correntes constitui justamente um elemento necessário para a concepção estratégica dessa recusa. Isso significa que, como Lukács já observou, há certamente uma "unidade ideal" das correntes irracionalistas, mas que essa unidade é determinada externamente - isto é, pela força política e teórica do socialismo científico - por isso, "o desenvolvimento do irracionalismo não apresenta, em quaisquer de suas etapas, um caráter 'imanente', como se, de uma certa maneira de colocar ou resolver os problemas, derivasse outra, impelida pela dialética interna do pensamento filosófico em movimento". ${ }^{11}$ Naturalmente, existem razões comuns no interior do irracionalismo para os quais Lukács voltou sua atenção: "A depreciação do entendimento e da razão, a glorificação da intuição, a gnosiologia aristocrática, a recusa do progresso histórico-social e a criação de mitos são, entre outros, motivos que encontramos em quase todo pensador

\footnotetext{
8 lbid., Aufbau-Verlag, p. 83; Werke 9, p. 93; ed. bras., idem, p. 93.

${ }^{9}$ Ibid., Aufbau-Verlag, p. 10; Werke 9, pp. 14-5; ed. bras., pp. 14-5.

${ }^{10} \mathrm{Cf}$. Holz, H. H. "Die Verteidigung des Elfenbeinturms", Blätter fur deutsche und internationale Politik 1979, n. 10 e 11, p. 1255 sgg. e 1373 seg.

${ }^{11}$ Lukács, G. op. cit., Aufbau-Verlag, p. 10; Werke 9, p. 14; ed. bras., p. 14.
} 
irracionalista". ${ }^{12}$ Mas esta lista já demonstra que as concepções básicas do irracionalismo não são, de forma imanente, capazes de desenvolvimento porque interrompem a relação cognitiva racional nos confrontos com a realidade, orientada para o progresso científico e para o processo de socialização, e ainda porque se retraem para uma autonomia intuitiva, decisionista ${ }^{13}$ e agnóstica do sujeito. $O$ significado central da posição teórico-cognitiva de toda ontologia ou, mais geralmente, de toda Weltanschauung, torna-se evidente aqui: sem uma teoria materialista clara do conhecimento, as concepções filosóficas totalizantes correm o perigo de serem vítimas de teoremas fundantes irracionais. O pluralismo de filosofemas concorrentes entre si, que se sucederam no palco da filosofia burguesa do pós-guerra, deve, portanto, ser considerado, entre outras coisas, como o efeito de seu irracionalismo oculto ou manifesto. Não há mais lugar para um desenvolvimento de conceitos (como o observamos, por exemplo, na passagem de Descartes a Spinoza a Leibniz ou nas etapas que vão de Kant a Fichte a Schelling a Hegel). $O$ irracionalismo passa a ser descritível apenas como uma sequência descontínua de destruição da racionalidade, que se renova constantemente e cujo único elo é constituído pelo fato de se opor totalmente à "saída do homem do estado de minoridade que ele deve imputar a si mesmo", ${ }^{14}$ mais concretamente, à autoconsciência teórica da classe trabalhadora que se emancipa. No entanto, a atomização da filosofia burguesa também repercute sobre a própria compreensão da história da filosofia: uma história da filosofia entendida como uma representação do desdobramento de problemas filosóficos, como em Hegel, Schelling e Feuerbach, torna-se assim impossível. No máximo, há apenas uma soma de opiniões escolásticas díspares, e mesmo os manuais burgueses mais recentes fizeram exatamente isso, sejam eles de Vorlander, Aster ou Glockner. A filosofia degenera no que Paul Feyerabend chamou de "o anarquismo da teoria do conhecimento", chegando até a elogiar este último como "racionalismo crítico".

Portanto, se, como acredito, é correta a afirmação de Lukács, segundo a qual a filosofia irracionalista quase sempre se apresenta com impulsos improvisados, determinados por situações externas, que se ampliam em medida crescente, então,

\footnotetext{
12 Aufbau-Verlag, p. 10 sg.; Werke 9, p. 15; ed. bras., p. 15.

13 Teoria elaborada pelo filósofo e jurista alemão Carl Schmitt (1888-1985), um dos teóricos do nazismo, segundo a qual em épocas de crise a desordem só se transforma em ordem por meio da decisão absoluta, que tem primazia sobre a ordem.

${ }^{14}$ Kant, I. "Was ist Aufklarung?", Berlinische Monatsschrift 1784, n. 12, p. 481.
} 
dessa situação deriva uma consequência estratégica para a crítica histórico-materialista da ideologia. Ela, portanto, deve repensar continuamente a crítica caso a caso, para combater de modo adequado os teoremas burgueses da moda no momento, e não deve se permitir em referir, simplesmente, a modelos clássicos de argumentação. Nesse sentido, para explicar, por exemplo, Sartre, Adorno ou Herbert Marcuse, no decorrer do debate, não basta recorrer às partes pertinentes do "São Max", uma vez que falta a esses autores e seus partidários a consciência da "unidade ideal" de "um conteúdo filosófico presente em todo o desenvolvimento", e que Lukács justamente caracterizou como "extremamente monótono e precário". ${ }^{15}$ Certamente, é sensato e necessário chamar constantemente a atenção para a reprodução de topoi tipicamente irracionais e para a sua origem, que a burguesia assume na transição, de seu papel prérevolucionário e modificador da sociedade para o papel pós-revolucionário e conservador do status.

4. Com isso, chego a uma tese sistemático-constitutiva de Lukács. O irracionalismo é a estratégia defensiva das classes dominantes, dirigida contra um desenvolvimento histórico, que faz nascer nas massas a consciência da desejabilidade e da possibilidade de uma mudança nas condições existentes de dominação (= condições de exploração). Dito em outras palavras, o irracionalismo faz aparecer as contradições que surgem entre o desenvolvimento das forças produtivas e as relações de produção como insuperáveis e fatais, ou então a distorce. A atitude que se opõe ao progresso social representa o momento crucial para a contradição entre o racionalismo e o irracionalismo. Não há irracionalismo orientado para o progresso, portanto, "progressista". Quero dizer que Lukács tem razão nisso e que é preciso ter isso em mente ao falar sobre o contraste entre Lukács e Bloch. Por outro lado - e isto Lukács também o dissecou -, nos sistemas racionais, orientados para o progresso e para a razão imanente no mundo, estão presentes elementos irracionais, que por sua vez são espelhamentos das contradições e imperfeições da forma de sociedade, ou a incompletude do saber, mas para os quais soluções irracionais não são oferecidas precisamente em sistemas racionais, mas sim devem ser buscadas em resoluções dialéticas. Lukács cita Vico, Rousseau e Herder como exemplos de elementos irracionais de filosofias que levam a tal dialética, e como contraexemplos

\footnotetext{
${ }^{15}$ Lukács, op. cit., Aufbau-Verlag, p. 11; Werke 9, p. 15; ed. bras., p. 15.
} 
irracionalistas, Pascal e Jacobi, e resume:

A constatação precisa de ambiguidade que encontramos nas obras dos mais importantes idealistas, da qual só poderiam estar livres os mais destacados materialistas, coloca-nos numa situação que nos obriga a não investigar a questão da afirmação ou negação da razão apenas sobre uma base puramente terminológica, menos ainda a partir de afirmações singulares que, isoladas do contexto geral e da intenção geral da filosofia considerada, também podem eventualmente soar como irracionalistas, mas a concentrar a nossa atenção precisamente sobre essa linha fundamental. ${ }^{16}$

Racionalismo e irracionalismo, portanto, têm suas diferenças específicas na concepção da essência da história. É racional buscar "investigar a legalidade do decurso histórico, do progresso histórico-social, descobrir e formular em conceito a razão na história e, precisamente, a razão imanente e própria à história humana, a razão no movimento autônomo da história geral". ${ }^{17}$ Daí resulta uma concepção de progresso que se compreende em si mesmo e fornece critérios para um desenvolvimento qualitativo avançado, podendo justificá-lo com tais motivos. $O$ contrário disso é (ou conduz ao) irracionalismo.

Do ponto de vista histórico-materialista, considero essa distinção correta. O que Lukács encontrou, por assim dizer empiricamente, tem uma base histórico-filosófica, segundo a qual Lukács pode sustentar que "a progressividade de qualquer situação ou qualquer tendência de desenvolvimento [é] algo objetivo, que age independentemente da consciência humana"18. São postos por universais históricos, portanto não ideais, cujo status na filosofia materialista precisa de alguns esclarecimentos (e este é um problema que ainda precisa ser resolvido e ao qual Lukács nunca dirigiu a atenção, nem mesmo em sua Ontologia).

Com o ponto de referência fornecido pelo termo progresso, Lukács indica também um critério de distinção no que se refere ao julgamento do legado filosófico: o problema básico da filosofia é tratar o ser e o mundo de uma perspectiva idealista ou materialista. O materialismo é sempre racionalista (ou, melhor se se preferir, nunca irracionalista, mesmo que se estenda ao irracional). $\mathrm{O}$ idealismo, por outro lado, pode ser racionalista, se preservar o irracional em uma racionalidade ideal, e então tende para a dialética: Descartes, Spinoza, Leibniz e Hegel são figuras emblemáticas. Ou se torna irracionalista, se hipostasiar os elementos irracionais do sistema de modo

16 Ibid., Aufbau-Verlag, p. 99; Werke 9, p. 110; ed. bras., p. 110.

17 Ibid., Aufbau-Verlag, p. 100; Werke 9, p. 111; ed. bras., p. 111.

18 Idem. 
metafísico: Schelling, Schopenhauer, Nietzsche e, sobretudo, os metafísicos póshegelianos tomaram esse caminho. O materialismo dialético deve aceitar os sistemas idealistas racionais como um legado, pois eles fornecem os elementos constitutivos de um espelhamento conceitual do mundo que pode ser tomado e elaborado pelo materialismo dialético, ou seja, interpretado e decifrado de um ponto de vista materialista. Eles representam modelos de construção da totalidade, que estabelecem a mediação histórica entre as ciências e a dialética como uma teoria do contexto geral. Isso significa que os sistemas idealistas racionais foram momentos do progresso teórico.

A história da filosofia, referindo-se a um progresso que se orienta ao ser pertencente à espécie humana social (Gattungswesen), divide-se de maneira significativa nas etapas de um desenvolvimento de problemas a elas imanentes, o que certamente não é uma história autônoma do espírito, mas uma função do desenvolvimento social. $O$ irracionalismo se destaca como mera reação desse continuum. Não podendo sequer perceber ou compreender o progresso, surge nele a tendência para a destruição. Lukács percebeu essa tendência mesmo onde ela ainda estava oculta, inconscientemente e absolutamente não desejada. Mesmo após o protesto de Bloch, ele permaneceu fiel à formulação provocativa de que haveria um "desenvolvimento de Schelling até Hitler". Certamente, com tal intransigência, muitos domínios culturais são deixados sem combate sob a hegemonia do inimigo. $O$ aviso expresso aqui não pode deixar de ser reconhecido. O perigo de usar bombas atômicas, mísseis e armas espaciais contra o progresso, em nome de uma concepção, verdade ou ordem moral considerada superior, expondo assim a existência de toda a humanidade ao aniquilamento, não surge apenas no momento em que os Schultz e Weinbergers escrevem seus planos estratégicos; eles já contêm o fundamento de sua não-verdade, seus proton pseudos ${ }^{19}$ em que o direito a uma concepção, verdade ou ordem moral considerada superior é reafirmado contra a razão. A luta contra o irracionalismo é uma luta pela vida e pela possível felicidade da humanidade. Lukács definiu claramente este contexto no prefácio da reimpressão de $A$ destruição da razão, em 1960, no qual ele escreve: "Hoje, a luta por paz ou guerra converteu-se no eixo de toda a prática humana do presente". E prossegue: "o movimento mundial pela paz podia ser apresentado como o movimento de massa até então mais poderoso em

\footnotetext{
19 Próton pseudos refere-se a premissas falsas, o erro original [N.T.].
} 
defesa da razão". ${ }^{20}$ Nisso estamos de acordo.

5. A crítica de Lukács ao irracionalismo se dirige à constituição do pensamento moderno. Para dizer a verdade, o irracionalismo em seu enfrentamento reacionário da racionalidade científica existe, para dizer a verdade, apenas a partir do momento em que se formou o tipo de ciência moderna e antiteológica, que se concretiza aos nossos olhos, de forma paradigmática, na figura de Galileu. As pré-formas medievais, como a do conflito entre Bernardo di Clairvaux e Abelardo, ou a da luta pela recepção de Aristóteles depois de 1200, ou ainda as das disputas universitárias em Paris do último terço do século XIII, têm alguns contornos ainda confusos; e mesmo a mística certamente irracional dos franciscanos espiritualistas e dos joaquimitas ${ }^{21}$ ou de Meister Eckart, a religiosidade dos anabatistas e de Thomas Münzer eram socialmente progressistas. A antítese entre irracionalismo (reacionário) e racionalidade (progressista) surge apenas a partir de um estágio muito preciso de desenvolvimento daquele processo de cientificização que Lukács descreveu em Estética, baseando-se na "desantropomorfização". ${ }^{22}$ Que o irracionalismo só pôde obter seu refinamento último e definitivo, como instrumento da luta ideológica de reação, no momento em que foram desenvolvidas as teorias racionais da totalidade (não só em geral, mas em particular também da história e da sociedade), que deveriam ser necessariamente as teorias de desenvolvimento e, portanto, também programas de superação das condições existentes. A partir desse instante, três momentos do irracionalismo podem ser identificados, por assim dizer, como constantes no interior de contextos mutáveis: ${ }^{23}$

1) A separação precisa dos fenômenos sociais de sua base econômica.

2) A subjetivação radical da história e a remoção radical de qualquer legalidade inerente ao seu curso.

3) A criação de mitos recorrendo à intuição.

20 lbid., Werke 9, p. 5; ed. bras., p. 5 (não está presente na edição alemã de 1954 [N.T]).

${ }^{21}$ Relativo a Joaquim de Fiore, abade cisterciense e filósofo místico, defensor do milenarismo e do advento da idade do Espírito Santo [N.T.].

22 Lukács, G. Die Eigenart des Asthetischen, Werke 11, Damstadt-Neuwied 1963, p. 139 sgg.

23 Lukács, G. Die Zerstörung der Vernunft, op. cit., p. 15 sgg.; Werke 9, p. 21 sgg.; ed. bras., p. 21; sobre as razões do mais recente irracionalismo op. cit., p. 20 sg.; Werke 9, p. 25 sg.; ed. bras., p. 25: 'Uma das tarefas sociais mais importantes da burguesia reacionária reside precisamente no fato de oferecer conforto aos indivíduos no contexto da visão de mundo, a ilusão de liberdade completa, a ilusão de independência pessoal em se sentir superior e em um nível moral e intelectual; com um comportamento em que a concepção de mundo ininterruptamente ligada à burguesia reacionária, em suas ações reais, se torna útil sem reservas". 
Com a dicotomia entre racionalidade e irracionalidade, Lukács foi recriminado por ter substituído, ou pelo menos posto de lado, a antítese mais básica do problema de fundo da filosofia, isto é, a antítese entre o materialismo e o idealismo. Considero esta recriminação injustificada. Racionalismo-irracionalismo não substitui 0 materialismo-idealismo, pelo contrário, designam modos da construção teórica e científica de uma concepção de mundo. Ambos os pares de conceitos nem mesmo se comportam de modo simétrico um com o outro. Na modernidade, não pode haver materialismo irracionalista, uma vez que uma concepção de mundo materialista sempre requer princípios de construção racional; e se ela faz propriamente seu o modo constitutivo do irracional, perde também seu caráter materialista. $O$ idealismo, pelo contrário, pode ser desenvolvido e fundado tanto de maneira racionalista quanto irracionalista - Hegel contra Schelling, Husserl contra Bergson poderiam ser tomados como modelos de comparação. Mas em um idealismo consequentemente racionalista há partes que tendem a uma reversão em uma compreensão materialista, ${ }^{24}$ de modo que também o materialismo pode extrair diretamente vantagens teóricas dos sistemas idealistas-racionalistas; o que é absolutamente impossível nas filosofias irracionalistas. A assimetria aqui acenada representa, a meu ver, um problema digno de reflexão em relação à determinação do status tipológico em relação ao sistema teórico-ideológico da filosofia; e propriamente tal investigação deveria fazer uso da clareza com que Lukács dissecou o contraste básico entre racionalismo e irracionalismo. ${ }^{25}$

O nível das filosofias irracionalistas é determinado pelo nível problemático dos sistemas racionais, contra os quais se orientam. É por isso que Lukács chega a uma periodização do irracionalismo burguês, que avança paralelamente ao progresso da ciência e da história e que explica, ao mesmo tempo, a mudança na qualidade das condições de desenvolvimento da filosofia, começando com o lluminismo até o socialismo científico. $\mathrm{O}$ irracionalismo moderno

surgiu e operou em permanente luta contra o materialismo e contra o método dialético. [...] surge, de maneira correspondente, em oposição ao

\footnotetext{
${ }^{24}$ Isso fica claro em Hegel, por isso Lênin frequentemente se referia a esse fato.

25 Faço uma diferença terminológica precisa: a racionalidade é um modus da maneira científica de construir teorias ou também um modus de constituição da realidade e do nosso conhecimento dela. Ao contrário, o irracionalismo é uma pseudoteoria ou uma afirmação abertamente fideísta e hipertrofiada em relação à concepção de mundo sobre um modus aparentemente possível e não racional de construção de teorias ou da realidade e de nosso conhecimento dela. Eu disse "pseudoteorético" porque mesmo os irracionalistas baseiam suas concepções em uma maneira racional de argumentar, quando eles não se baseiam simplesmente em uma iluminação ou em um ato de fé, e, dessa forma, certamente, também excluem a comunicação sobre suas concepções.
} 
conceito histórico-dialético idealista de progresso; trata-se do caminho de Schelling a Kierkegaard e que é, ao mesmo tempo, o caminho que vai da reação feudal provocada pela Revolução Francesa à hostilidade burguesa contra o progresso. ${ }^{26}$

O primeiro período de irracionalismo possui, no interior dos problemas objetivos das insuficiências de um materialismo mecânico e de uma dialética conceitual idealista, objetos dos quais se pode de modo legítimo desdobrar, por assim dizer, à altura do tempo, sua própria crítica filosófica das filosofias progressistas. Schelling, o maior antagonista de Hegel, obtém uma justiça parcial com as aporias nas quais Hegel se emaranhou, assim como, mas em menor medida, Kierkegaard. ${ }^{27}$ Isso determina a importância filosófica que possuem, apesar de sua tendência reacionária.

Com as Jornadas de Junho do proletariado parisiense e, sobretudo, com a Comuna de Paris: a partir de agora a concepção de mundo do proletariado, o materialismo histórico e dialético, passa à condição de adversário, cuja natureza essencial determina o desenvolvimento do irracionalismo. O novo período terá Nietzsche como o primeiro e mais importante representante. ${ }^{28}$

$\mathrm{Na}$ realidade, existe uma ciência da história e da sua legalidade, e uma concepção da dialética materialista como uma ciência do contexto geral, vale dizer, a dialética da natureza. A rejeição filosófica desta teoria, que nasce de uma práxis orientada para a transformação social, deve limitar-se à reprodução de filosofias superadas, se pretende escapar ao efeito que exerce o materialismo dialético, isto é, o de ser o próprio tempo aprendido com o pensamento. $\mathrm{O}$ epigonismo e a renúncia explícita à exigência de reconhecer a verdade significam bater em retirada:

\begin{abstract}
Na primeira etapa ainda é possível uma crítica relativamente justificada, que mostra os reais defeitos e limites da dialética idealista. Na segunda, entretanto, vemos que os filósofos burgueses já estavam privados da capacidade e da vontade de conhecer o adversário, de empreender esforços para refutá-lo seriamente. ${ }^{29}$
\end{abstract}

Lukács estava bem convencido do fato "que a concepção de mundo que se manifesta na agitação e na propaganda nacional-socialista representa o fruto cultivado organicamente e necessariamente nascido do desenvolvimento ideológico da burguesia alemã na era do imperialismo". ${ }^{30} \mathrm{E}$, como mostra seu posfácio e $A$ destruição da razão, ${ }^{31}$ ele sustentava, com igual razão, o perigo endêmico de o imperialismo não

${ }^{26}$ Lukács, G. Die Zerstörung der Vernunft, op. cit., p. 8; Werke 9, p. 12; ed. bras., p. 12.

${ }^{27}$ Cf. Bloch, E. Subjek:-Objekt Erliuterungen Zu Hegel, Berlin 1951, pp. 357-377; Gesamtausgabe vol. 8, Frankfurt a.M. 1962, pp. 379-400.

${ }^{28}$ Lukács, G. Die Zerstörung der Vernunft, op. cit., p. 8; Werke 9, p. 12; ed. bras., p. 12.

29 Ibid., op. cit., p. 8 sg.; Werke 9, p. 12 sg.; ed. bras., p. 12.

30 Lukács, G. Wie ist die faschistische Philosophie In Deutschland entstanden?, Budapest 1982, p. 42.

${ }^{31}$ Lukács, G.Die Zerstörung der Vernunft, op. cit., p. 603 seg.; Werke 9, p. 663 sgg; ed. bras., p. 663. 
ser superado com a aparente derrubada do fascismo em 1945. A filosofia burguesa contemporânea serve (queira ou não) em seus traços essenciais do irracionalismo constitutivo tanto para a apologia do imperialismo do pós-guerra quanto para preparar (queira ou não) o fascismo antes de 1933 e para legitimá-lo depois. A crítica do irracionalismo (que - com todas as diferenciações das posições filosóficas e suas funções políticas - compreende em si a crítica do racionalismo aparente das filosofias neopositivistas analíticas e das assim chamadas "críticas") continua a ser a principal tarefa crítico-ideológica na luta contra o imperialismo e o fascismo também na segunda metade do século XX; aqui, Lukács marcou uma linha divisória para o marxismo que não deve ser abandonada. ${ }^{32}$

6. Em conexão íntima com esta função política e ideológica da crítica do irracionalismo e com o desenvolvimento de seu conceito de progresso para a filosofia, literatura e arte, para Lukács, se põe a questão de uma ontologia dialética no âmbito da sistematicidade do materialismo dialético e histórico. As cadeias de argumentações da destruição irracionalista do primado teórico da razão podem ser reduzidas a quatro teses centrais:

a) O mundo em sua totalidade não pode ser representado em modelos científicos, principalmente construídos de forma racional, devido à sua infinitude intensiva e extensiva, portanto, só pode ser objeto de uma representação imaginativa (intuição intelectual, visão de ideias etc.).

b) Todos os saberes teóricos e sobretudo os modelos ideológicos da filosofia, da religião, da arte e da moral são historicamente relativos e não se deixam medir com um conceito de verdade que significa a adaequatio rei et intellectus (suspeita ideológica total).

c) A subjetividade das condições de um conhecimento possível tem como consequência que a coisa em si (a essência, a própria coisa) permanece inescrutável e que o critério do nosso conhecimento e do nosso agir só pode ser encontrado em nós mesmos (idealismo transcendental e agnosticismo).

d) Existe uma desigualdade geral entre a razão teórica e a razão prática; por isso, não é possível reconduzir os juízos de valor até os juízos sobre as coisas e,

\footnotetext{
${ }^{32}$ Cf. Losurdo, D. Lukács e la distruzione della ragione, Convegno su Lukács nel centenario della nascita,
} Urbino, pp. 13-15, febbraio, 1985. 
portanto, em última análise, a toda a esfera do agir permanece arbitrária (decisionismo).

Embora esses quatro pontos gerais de argumentação possam ser formulados como restrições puramente metodológicas ou crítico-cognitivas, em sua base ainda existem supostos ontológicos aos quais é preciso se opor quando se deve fundamentar uma crítica ao irracionalismo. As quatro teses mencionadas acima correspondem a quatro teoremas ontológicos:

1) Não há nenhuma estrutura racional no complexo do mundo infinito; o singular incomensurável e, portanto, alógico, tem primazia em relação ao todo.

2) Não há nenhuma relação em nível de regra entre as situações que se sucedem no mundo e a história da humanidade e, por conseguinte, não há nem mesmo uma ciência da história.

3) O pensamento e a faculdade cognitiva, ou simplesmente a consciência, não são de forma alguma de um gênero diferente do ser material e independentes dele.

4) Não há mediação entre a ordem (fictícia) da natureza no modus de necessidade e o agir dos homens no modo de liberdade.

Essas suposições básicas têm suas raízes nas antinomias do intelecto puro e, em primeiro lugar, não apresentam de forma alguma o sinal de irracionalismo. Portanto, é ainda mais importante descobrir que a tendência para a destruição da razão já está colocada neles. Uma crítica completa do irracionalismo remete, portanto, para uma comparação com as premissas ontológicas do nominalismo, relativismo e filosofia transcendental. E foi exatamente essa estrada que Lukács percorreu.

Aqui não se trata de retomar a concepção lukácsiana de ontologia; para tal exame, ver os excelentes trabalhos de Guido Oldrini. ${ }^{33} \mathrm{Em}$ vez, neste ponto, gostaria de destacar a função que uma ontologia pode ter para a crítica do irracionalismo e, portanto, de esclarecer, a partir deste contexto, o interesse de Lukács pelos problemas

${ }^{33}$ Cf. Oldrini, G. Giovane Lukács o Lukács maturo?", ibid. Dello stesso, "Le basi teoretiche del Lukács della maturità", In G. Oldrini (a cura di), Il marxismo della maturità di Lukács, Napoli 1983. Não posso aceitar a tese de Nicolas Tertulian, segundo a qual Lukács teria desenvolvido simultaneamente uma ontologia "entre" Heidegger e Hartmann, e há semelhanças evidentes do problema entre Sartre e sua ontologia. Cf. Tertulian, N. "La rinascita dell'ontologia: Hartmann, Heidegger, Lukács", In Critica marxista, 1984, n. 3, p. 125 sgg. 
ontológicos (ou pelo menos como essa é configurada de algum outro modo em sua obra, como na Estética).

Logo no início do capítulo sobre Hegel, na Ontologia do ser social, a relação entre racionalismo e irracionalismo é colocada no centro e, portanto, a conexão com $A$ destruição da razão é estabelecida: "domínio e prioridade ontológica da razão, num mundo formado pela Revolução Francesa, ou, mais concretamente, pelo matiz um tanto diferente com que Napoleão a realizou. Esse tipo de realização da revolução confronta toda a Europa com o problema da sociedade burguesa em expansão: em sua contraditoriedade imanente, numa nova realidade, em face da qual o reino iluminista da razão - enquanto centro do pensamento filosófico - necessariamente falharia de imediato". ${ }^{34} \mathrm{O}$ irracionalismo do romantismo é entendido como uma inflexão na ontologia, como um ensinamento sobre a resolução das contradições reais em uma harmonia suprarracional ideal ou em um ser-uno místico, que recoloca na utopia voltada ao passado, em uma comunidade medieval de crentes, seu parâmetro histórico. ${ }^{35}$ Por outra parte, o que destaca a importância de Hegel é "que ele pretende demonstrar filosoficamente que o próprio presente é um reino da razão, o que forçosamente eleva a contradição à condição de categoria ontológica e lógicognosiológica central". ${ }^{36} \mathrm{O}$ conceito de razão foi, portanto, consideravelmente ampliado em relação ao da filosofia iluminista. Se "a contradição forma o princípio ontológico último", ${ }^{37}$ então não é mais possível uma ontologia à moda antiga como a Christian Wolff, que se apoia inteiramente no princípio da contradição negada ${ }^{38}$ e que, por via de consequências, faz coincidir a ontologia enquanto formal (scientia entis em geral) com a lógica formal: "Quer ser chamada de filosofia primeira, porque fornece os primeiros princípios e os conceitos primeiros que são usados no pensamento racional (ratiocinando)". ${ }^{39}$

A esse respeito, Hegel desenvolve a unidade de lógica e ontologia como algo da

34 Lukács, G. Zur ontologie des gesellschaftlichen Seins. - Hegels falsche und echie Ontologie, Darmstadt-Neuwied, 1971, p. 5.; ed.bras. Para um ontologia do ser social, I; São Paulo: Boitempo, 2012; pp. 181-2.

${ }^{35}$ Por mais diferentes e mesmo politicamente de direção oposta que sejam os programas relativos à contradição entre comunidade e sociedade em Ferdinand Tönnies e a nova comunidade que na humanidade ao mesmo tempo comunista e libertada e espiritualmente redimida no Espírito da utopia de Ernst Bloch, eles têm suas raízes nesta crítica romântica da sociedade burguesa.

${ }^{36}$ Lukács, G. Zur Ontologie... - Hegel, op. cit., p. 6; ed. bras. Para uma ontologia.... op. cit. p. 182.

37 Ibid.

38 Wolff, C. Philosophia prima sive Ontologia, Frankfurt A. M. 1762, p. 15 sgg. (7 spg.).

39 Ibid., p. 1 (§1). 
temporalidade e, portanto, como contraditoriedade, já reconhecida na época de Zenão e Platão, do ao mesmo tempo não-ser-mais e não-ser-ainda do momento, na mudança: apesar disso, nele "a dinâmica das contradições dialéticas não é um simples devir universal, [...], mas [...] a primeira articulação da sequência dialética e da historicidade real". ${ }^{40}$

O conceito de razão de Hegel contém em si a contraditoriedade entre o não-mais e o não-ainda em sua passagem e entre a determinidade finita e a mediatidade infinita do singular. Deste modo, para ele, "a razão [pode se tornar] o princípio último do ser e do devir da natureza e da sociedade". ${ }^{41}$ Ele resolve as tarefas de uma filosofia racional, constituindo uma totalidade, uma processualidade, uma unidade entre natureza e espírito (como subjetivo $=$ consciência, como objetivo $=$ manifestações sociais), entre realidade objetiva e ações subjetivas (atividade) de tal modo que faz desaparecer os dilemas irracionalistas. A solução idealista de Hegel, que culmina na identidade da lógica (dialética) e da ontologia, está, na verdade, errada, mas o problema em si está colocado de maneira correta. Sob o primado da razão, uma ontologia racional desenvolverá a racionalidade $=$ logicidade do mundo, descobrindo assim a razão da correspondência entre as formas de pensamento e as formas de ser, portanto, uma teoria do conhecimento realista, a possibilidade de um espelhamento científico do mundo e o progresso sensatamente planificável:

\begin{abstract}
por um lado, as verdadeiras conexões ontológicas recebem em Hegel sua expressão adequada no pensamento tão somente na forma de categorias lógicas; por outro, as categorias lógicas não são concebidas como simples determinações do pensamento, mas devem ser entendidas como componentes dinâmicos do movimento essencial da realidade, como graus ou etapas no caminho do espírito para realizar a si mesmo. ${ }^{42}$
\end{abstract}

No entanto, esse programa hegeliano pode mostrar, apenas em sua inversão materialista e, portanto, em Marx, as suas reais consequências teórico-científicas e teóricas do agir: depois, isto é, quando a práxis social é determinada como o lugar e descrita em suas estruturas categoriais, em que aparece a lógica dialética (que inclui, isto é, as contradições) do mundo e com isso a gênese das formas de pensamento a partir das formas de ser. Assim, Lukács procede do movimento da própria coisa, de Hegel a Marx até a categoria ontológica central do trabalho, ${ }^{43}$ em que a relação sujeito-

\footnotetext{
${ }^{40}$ Lukács, Zur Ontologie... - Hegel, op. cit., p. 7; ed. bras. Para uma ontologia... op. cit. p. 182.

41 lbid., p. 9; p. 184.

42 Ibid., p. 26; pp. 197-8.

${ }^{43}$ Lukács,G. Zur Ontologie... - Arbeit, Darmstadt - Neuwied, 1973, p. 13; ed. bras. Para uma ontologia
} 
objeto recebe uma qualidade nova e se cria a premissa da possibilidade de uma representação ontológica das condições ônticas (substanciais, essenciais e materiais).

7. Neste ponto, porém, não se pode ignorar que Lukács falhou em cumprir o seu programa, ou seja, em estabelecer um fundamento ontológico para uma dialética materialista, precisamente porque, no esforço de evitar a construção idealista de identidade entre a forma do ser e a forma de conceito em Hegel, recaiu em posições dualistas, sob a premissa de que ele ainda pode sustentar a racionalidade do mundo apenas de um modo filosoficamente insatisfatório e ingênuo-realista. $O$ dualismo renovado encontra sua expressão na contraposição da função do pensamento de tornar homogênea a multiplicidade da realidade, isto é, conduzi-la a uma sistemática do universal e do particular, e na diversidade fundamental das entidades materiais, singulares e, de vez em quando, de suas relações específicas incomensuráveis: "a lógica cria um meio homogêneo de pensamento, cuja estrutura deve ser qualitativamente diversa da realidade, que é em si heterogênea". ${ }^{44} \mathrm{~A}$ homogeneidade do mundo conceitual é fundada (segundo a interpretação lukácsiana de Hegel) na reflexão, na subsunção do singular heterogêneo sob as determinações da reflexão, que Lukács denomina a "mais importante descoberta metodológica de Hegel" ${ }^{45}$ Fazendo Lukács da lógica da essência - portanto a parte central da Ciência da Lógica - a chave para a compreensão de Hegel, ${ }^{46}$ o processo do espelhamento da realidade através do pensamento deve parecer idealista para ele; e esse idealismo certamente seria apenas um ulterior desenvolvimento dialético da filosofia transcendental de Kant:

O procedimento "natural" do ser humano, nesse tocante, é que, encontrando na realidade com que se defronta objetos singulares, busque apreendê-los na forma imediata, dada, em que aparecem, isto é, isoladamente. Essa tentativa, todavia, produz espontaneamente 0 seu contrário, o

do ser social, II, São Paulo: Boitempo, 2013, p. 47.

${ }^{44}$ Lukács, G. Zur Ontologie des geselischaftlichen Seins. - Hegel, op. cit., p. 103; ed.bras. Para uma ontologia..., op. cit., p. 221 . O problema da unidade entre unidade e diferença foi tratado dialeticamente por Lenin, "Zur Frage der Dialektik", e mais detalhadamente em Lênin, Werke (LW) vol. 38. Lenin reconheceu (em concordância com Hegel) a generosidade do singular como ponto nodal de uma compreensão dialética da realidade. Lukács, por outro lado, na rigorosa divisão da homogeneidade do conceito e da heterogeneidade do ser, pode ter sido influenciado por reflexões neokantianas (Lask?). Não se deve ignorar que a dificuldade de uma adequada concepção dialética do concreto geral entre os filósofos marxistas quase sempre criou confusão, e a expressão mais significativa da qual talvez seja a categoria dominante de "tauto-eterologia", não se trata de um dialeto, mas de um gêmeo siamês, unido, imóvel e inútil, mas se dividido não pode sobreviver. Ver Della Volpe, G. Logica come scienza positive, Messina-Florence, 1956.

${ }^{45}$ Lukács, G. Zur Ontologie..., Hegel, op. cit., p. 84; ed. bras. Para uma ontologia...; op. cit., p. 246.

46 Minha opinião, que este é um caminho errado para Hegel, é expressa em "Hegel - systematisch gelesen"', Dialektik 2, Köln, 1981, p. 20 ff.; e mais detalhadamente em Struktur und Aufbau des hegelschen systems, Köln. 1985. 
relacionamento recíproco dos objetos que aparecem imediatamente. ${ }^{47}$

Isso significa: reconhecendo, produzimos a unidade do mundo na reflexão, nós o tornamos homogêneo.

A fim de manter essa concepção de uniformização conceitual de um mundo que é inevitavelmente múltiplo (heterogêneo) em si mesmo, Lukács deve novamente separar a lógica da ontologia, uma da outra (e ele também imputa a Hegel a dualidade de uma ontologia prima, por assim dizer teórico-objetiva e uma segunda lógicoconceitual). A unidade hegeliana da lógica e da ontologia, esta expressão da logicidade do mundo, passa a ser criticada, pois Hegel teria sobrecarregado, na fusão das duas ontologias,

as categorias lógicas de conteúdos ontológicos, englobando incorretamente em suas articulações relações ontológicas, além de ter deformado de várias maneiras os importantíssimos conhecimentos ontológicos novos ao forçar seu enquadramento dentro de formas lógicas. ${ }^{48}$

A objeção levantada à identificação hegeliana do conceito e do ser na ideia (como unidade de conceito e realidade) agora leva a ter que separar ambos novamente a tal ponto que a barricada ontológica contra o irracionalismo, em vista da categoria decisiva da totalidade (ver parágrafo 6 , teorema 1), começa a vacilar: "quanto mais o pensamento elabora a racionalidade do real, tanto mais se acerca da ilusão de que é possível captar a inteira realidade como sistema unitário, racional" ${ }^{49}$ O fato que então, como única racionalidade dialética possível do todo, resta apenas a totalização teleológica do trabalho - com uma superestimação da teleologia e uma negligência do objeto natural do trabalho - só pode ser mencionada aqui de maneira marginal. $O$ fato de Lukács se limitar a resgatar formas na dialética da natureza, sem colocar uma

\footnotetext{
47 Lukács, G. Zur Ontologie... - Hegel, op. cit., p. 85; ed. bras. Para uma ontologia...; op. cit., p. 247. Lukács se equivoca na legitimidade de sua interpretação de Hegel, encontrando exposta em \$419 da Enciclopédia (portanto da filosofia do espírito subjetivo e nesta da fenomenologia I grau: consciência) ao ver não a gênese do conhecimento da reflexão (Reflexividade), mas (de modo ambíguo) "a gênese das determinações de reflexão". As determinações de reflexão são, porém - antes de serem compreendidas - já momentos das estruturas do ser = da essência (como relação absoluta): "A essência... é a referência a si mesma, apenas na medida em que é referência a outro... $O$ ser não desapareceu; mas primeiro, a essência como uma simples referência a si mesma é o ser; por outra parte, porém, o ser é, de acordo com sua determinação unilateral de imediatidade, rebaixado a algo apenas negativo, a uma aparência. - A essência é, portanto, o ser como um aparecer em si mesma... O ponto de vista da essência é, em suma, o ponto de vista da reflexão". Hegel, G.W.F 'Enzyklopädie der philosophischen Wissenschaften, \$112 e mais, Frankfurt A.M. 1970, Werkausgabe vol. 8, pág. 231 sg. Ver também Enzyklopädie $\$ 149$ e em mais detalhes Wissenschaft der Logik II, op. cit., vol. 6, Frankfurt a.M. 1969, p. $217 \mathrm{sg}$. A gênese do conhecimento da reflexão (reflexividade) em Hegel não tem nenhum papel para a constituição ontológica do ser como reflexivo.

${ }^{48}$ Lukács, Zur Ontologie... - Hegel, op. cit., p. 44; ed. bras. Para uma ontologia...; op. cit., p. 212.

49 Ibid., p. 109; Para uma ontologia..., op. cit., p. 266.
} 
dialética sistemática da natureza na base de sua ontologia, leva-o, a esse respeito, contra sua vontade, próximo da Escola de Frankfurt e de outras correntes de pensamento e à fundação da dialética única ou primariamente na relação de trabalho. ${ }^{50}$

Sem considerar em particular muitas convicções importantes e corretas, pareceme que a Ontologia do ser socia/perdeu seu propósito, isto é, a consolidação da crítica do irracionalismo, portanto, propriamente seu objeto, isto é, a construção da estrutura dialética do ser. Com isso, no entanto, a tarefa de uma ontologia marxista não é de forma alguma rejeitada; e podemos considerar o mérito de Lukács por ter recordado com firmeza esta tarefa no âmbito da questão da nossa consciência. Sim, acho que em sua Estética, ele contribuiu mais para uma ontologia dialética, com a elaboração da teoria da mimesis do que na própria Ontologia. ${ }^{51}$ Visto que a constituição dialética do ser pode ser descrita nos diferentes planos do ser, de cada vez como uma relação particular de espelhamento, que se constitui através das diferentes formas de movimento da matéria; e a reflexão, pela qual se define o espelhamento, nada mais é do que a relação universal, na qual todas os entes estão em relação recíproca, e esta constitui a unidade da multiplicidade ${ }^{52}$ e a reflexão, segundo o qual o reflexo é definido, nada mais é do que a relação universal, na qual todas os entes se opõem e que cria a unidade da multiplicidade. Portanto, foi necessário desenvolver uma ontologia dialética como uma teoria da reflexão, no interior da qual (como a relação mais genérica do ser ou da natureza) a práxis e a unidade de teoria e práxis encontram como modus particular de reflexão o seu lugar sistemático (em vez de se tornarem autônomas na forma de ontologia de trabalho). O grande filósofo búlgaro Todor Pawlow, já em 1936, projetou uma teoria do espelhamento como um sistema universal da dialética da natureza e da teoria do conhecimento; obra considerada até agora um modelo para a literatura marxista. ${ }^{53}$ As análises de Lukács da mimesis podem ser compreendidas como uma parte essencial de tal sistema, como uma representação da gênese natural do trabalho social e a representação conceitual do mundo. Uma ontologia materialista pode atrair convicções irrenunciáveis e múltiplos estímulos.

\footnotetext{
${ }^{50}$ Até que ponto as velhas posições da História e consciência de classe persistem aqui é uma questão que deixo em aberto.

${ }^{51}$ Cf. Holz, H.H. I/ problema della mimesis nell'estetica di Lukács, Convegno di Urbino, op. cit.

52 Cf. Holz, H. H. Dialektik und Widerspiegelung, Köln 1983.

53 Pawlow, T. Die Widerspiegelungstheorie, Berlim, 1973 (edição russa, Moscou, 1962).
} 
Como citar:

HOLZ, Hans Heinz. György Lukács e o problema do irracionalismo. Tradução de Ronaldo Vielmi Fortes. Verinotio, Rio das Ostras, v. 27, n. 1, pp. 125-145, jan./jun 2021. 